\title{
Successful weight maintainers among young adults-A ten-year prospective population study
}

\author{
Ulla Kärkkäinen $^{\mathrm{a}, *}$, Linda Mustelin ${ }^{\mathrm{a}, \mathrm{b}}$, Anu Raevuori ${ }^{\mathrm{a}, \mathrm{c}}$, Jaakko Kaprio ${ }^{\mathrm{a}, \mathrm{b}}$, Anna Keski-Rahkonen ${ }^{\mathrm{a}}$ \\ ${ }^{\text {a }}$ Department of Public Health, Clinicum, University of Helsinki, Finland \\ ${ }^{\mathrm{b}}$ Institute for Molecular Medicine FIMM, University of Helsinki, Helsinki, Finland \\ ${ }^{\mathrm{c}}$ Department of Adolescent Psychiatry, Helsinki University Central Hospital, Helsinki, Finland
}

\section{A R T I C L E I N F O}

\section{Keywords:}

Longitudinal

Weight maintenance

Weight gain

Young adults

General population

Prospective cohort

\begin{abstract}
A B S T R A C T
Objectives: To assess factors associated with successful weight maintenance over ten years in a prospective general population sample of young adults.

Material and methods: Our study comprised 2452 women and 2227 men born in 1975-1979 (mean age at baseline 24 years, attrition $27.1 \%$ ). Weight maintenance was defined as weight maintained within $\pm 5 \%$ of baseline body mass index (BMI). We examined the role of various sociodemographic and lifestyle factors in successful weight maintenance.

Results: Relatively few young adults were able to maintain their weight over ten years $(28.6 \%$ of women vs. $23.0 \%$ of men); net weight loss was uncommon (7.5\% and 3.8\%). Most participants gained weight (mean annual weight gain was $0.9 \mathrm{~kg}$ in women and $1.0 \mathrm{~kg}$ in men). Among women, exercise was associated with successful weight maintenance, but having two or more children, frequent use of sweet drinks, irregular eating, history of dieting (intentional weight loss) and low life satisfaction were associated with weight gain. Among men, higher baseline BMI and higher education were associated with successful weight maintenance, whereas irregular eating, history of dieting and smoking were associated with weight gain.

Conclusions: Only about a quarter of young adults were able to resist weight gain. Regular eating and having no history of dieting were associated with successful weight maintenance in young women and men.
\end{abstract}

\section{Introduction}

Overweight and obesity have rapidly increased among young adults throughout the world (Thompson, 2008). Increasing average weight is a complex, multifactorial problem attributed to socioeconomic, lifestyle, and dietary changes (Arabshahi, Lahmann, Williams, \& van der Pols, 2014). Because the long-term success rate of weight loss is at best modest (Powell, Calvin 3rd, \& Calvin Jr, 2007), and dieting can predict future weight gain (Dulloo, Jacquet, \& Montani, 2012; Pietilainen, Saarni, Kaprio, \& Rissanen, 2012; Powell et al., 2007), weight maintenance is important. Paying attention to factors that help to maintain a steady weight would be a potential population-level prevention approach (Ball, Brown, \& Crawford, 2002; Lindvall et al., 2013; Nafziger et al., 2007; Ramage, Farmer, Eccles, \& McCargar, 2014; Wing \& Phelan, 2005). Yet, our understanding of such factors is incomplete.

Previous longitudinal research has proposed various factors that influence successful weight maintenance. Such factors involve baseline weight, social factors, such as high socioeconomic status, education and occupation, and having fewer children (Ball et al., 2002; Kahn \&
Williamson, 1990; Nafziger et al., 2007). Also, general psychological well-being (Chiriboga et al., 2008), physical activity (Brown, Kabir, Clark, \& Gomersall, 2016; Gordon-Larsen et al., 2009; Hankinson et al., 2010; Schmitz, Jacobs Jr, Leon, Schreiner, \& Sternfeld, 2000; Wing \& Phelan, 2005) and a diet rich in unprocessed cereal, fruits and vegetables (Karfopoulou et al., 2017), can promote successful weight maintenance. In contrast, a host of lifestyle factors pose a threat to weight maintenance: a sedentary lifestyle (Ball et al., 2002; Brown et al., 2016; Chiriboga et al., 2008), takeaway food (Ball et al., 2002; Pereira et al., 2005), sweet drinks (Karfopoulou et al., 2017; Malik, Pan, Willett, \& Hu, 2013), alcohol consumption and smoking (Karfopoulou et al., 2017; Saarni, Pietilainen, Kantonen, Rissanen, \& Kaprio, 2009), disinhibited eating (Wing \& Phelan, 2005), dieting and weight fluctuations (Brown et al., 2016; Logel, Stinson, \& Brochu, 2015; St Jeor et al., 1995; St Jeor et al., 1997). Finally, factors influencing weight maintenance appear to vary depending on cultural factors, age and sex (Chiriboga et al., 2008; Lindvall et al., 2013).

To date, it remains controversial whether factors that explain successful weight loss or maintenance differ in women and men (Stroebele-

\footnotetext{
* Corresponding author at: Dept of Public Health, PL 20, Tukholmankatu 8 B, 00014, University of Helsinki, Finland.

E-mail address: ulla.karkkainen@helsinki.fi (U. Kärkkäinen).
} 
Benschop et al., 2013). Yet, our previous study showed that women and men perceive their weight differently (Kärkkäinen, Mustelin, Raevuori, Kaprio, \& Keski-Rahkonen, 2016), and other researchers have suggested that women and men respond differently to weight maintenance and weight loss approaches (Robertson et al., 2016).

After weight loss has been achieved, healthy habits, such as regular eating patterns, regular breakfast eating, healthy food choices and physical activity appear to be important predictors of weight maintenance (Elfhag \& Rossner, 2005; Keski-Rahkonen, Kaprio, Rissanen, Virkkunen, \& Rose, 2003). Because maintaining weight loss is difficult (Powell et al., 2007), the focus should be on initial weight maintenance.

Young adulthood, a time period where remarkable life transitions, such as marriage, pregnancies, and changes in employment typically occur, may be the most critical period for weight change (Adams et al., 2014; Arabshahi et al., 2014; Dutton et al., 2016). Weight gain in young adulthood is strongly related to higher mortality (Adams et al., 2014). Yet, few studies have addressed young adults and we are aware of no studies of weight maintenance among young men. Our aim was to study factors at mean age 24 associated with long-term successful weight maintenance. Therefore, we examined the role of baseline weight and various sociodemographic and lifestyle characteristics in long-term weight maintenance in a nationwide cohort of young women and men. A recent study by Brown and colleagues (Brown et al., 2016) explored determinants of long-term maintenance in a healthy BMI range among young women with similar aims. Our study expands on their aims and unanswered questions with data of energy balance at baseline, more detailed information of successful weight maintenance ( $\pm 5 \%$ BMI) and by including both young women and men.

\section{Materials and methods}

\subsection{Study population}

The participants for this study were identified from FinnTwin16, a nationwide longitudinal study of Finnish twins born between October 1974 and December 1979 identified from the Central Population Registry of Finland (Kaprio, Pulkkinen, \& Rose, 2002). In total, FinnTwin16 cohort study consists of five waves of data collection when the twins were 16 (Wave 1), 17 (Wave 2), 18.5 (Wave 3), 22-28 (Wave 4) and 31-37 (Wave 5) years old; participation rates were high throughout (Kaprio, 2013).

Analyses reported in this study are based on information collected at wave 4 (mean age 24) and wave 5 (mean age 34). This current study was conducted from 2000 till 2011 as part of the FinnTwin16 cohort study. Wave 4 data was collected between 2000 and 2002, and wave 5 data in 2010 to 2011 . The response rates were very high in both waves (80-90\%).

In this study, we wanted to explore factors at mean age 24 associated with long-term weight maintenance in the general population. Therefore, we studied twins as individuals by adjusting correlated observations within twin pairs in this study. The self-report questionnaires addressed height and weight, various health behaviors, and other health-related factors (Kaprio, 2013). Height and weight were addressed at mean ages 24 and 34. Various health behaviors and other health related factors were addressed at mean age 24 .

\subsection{Ethics}

The study was conducted according to the standards of the Declaration of Helsinki and was approved by the ethics committee of the Central Finland Hospital district, Helsinki and Uusimaa Hospital Districts and IRB, Indiana University, Bloomington, IN.

\subsection{Exclusions and attrition}

We excluded individuals who self-reported suffering from chronic, potentially weight-affecting illnesses at mean age 24 or $34(n=285)$ : these included mental retardation; cerebral palsy and other mobility disorders; malignancies; hemolytic anemia; inflammatory bowel disease, celiac disease, and other severe digestive disorders; thyroid disorders; diabetes; sarcoidosis; mitochondrial myopathy; multiple sclerosis; schizophrenia, schizoaffective and bipolar disorders; systemic lupus erythematosus (SLE); multiple traumas; HIV infection.

At mean age 24 (wave 4), from 2651 women and 2313 men we excluded participants who self-reported chronic, potentially weight affecting illnesses and whose baseline information on weight or height was missing ( $\mathrm{n}=37$ women and $54 \mathrm{men}$ ). The analyses at mean age 24 were conducted using 2452 women and 2227 men.

At mean age 34 (wave 5), 10 years later information of participants with no-chronic, potentially weight related illnesses, and weight and height was available from 1916 women and 1574 men. The overall attrition rate between data collection waves at 24 and 34 y was $21.9 \%$ among women and $29.3 \%$ among men.

\subsection{Attrition analyses}

Our study spanned over a period of ten years: $27.1 \%$ of our respondents (21.9\% of women and $29.3 \%$ of men) were lost to follow-up between mean ages 24 and 34 (waves 4 and 5). In attrition analyses, women responding at mean age 34 did not differ from non-responders with respect to BMI or history of dieting. Men with higher BMI and history of dieting at mean age 24 were more likely to be lost to followup. In both sexes, respondents at mean age 34 were statistically significantly more educated, had fewer children, were more likely to live in a city and less likely to smoke (full attrition analysis available from the author upon request).

\subsection{Measurements}

\subsubsection{Body Mass Index (BMI) and Waist circumference}

BMI $\left(\mathrm{kg} / \mathrm{m}^{2}\right)$ was calculated from self-reported weight and height at mean age 24 and 34. For assessment of waist circumference, subjects were sent a tape measure along with illustrated instructions. In a validation sample (Saarni et al., 2009), the agreement between actual measurements and self-report was high. The interclass correlation for BMI was 0.89 (mean difference was $0.93 \mathrm{~kg} / \mathrm{m}^{2}$ ) and 0.75 for waist circumference (mean difference was $2.48 \mathrm{~cm}$ ). We used the standard WHO definitions of "underweight" (BMI $<19.5 \mathrm{~kg} / \mathrm{m}^{2}$ ), "normal weight" (BMI 19.5-24.9 kg/m²), "overweight" (BMI $25-29.9 \mathrm{~kg} / \mathrm{m}^{2}$ ) and "obesity" (BMI > $29.9 \mathrm{~kg} / \mathrm{m}^{2}$ ).

\subsubsection{Weight maintenance}

We defined participants as successful weight maintainers if their weight at mean age 34 (wave 5) was within $\pm 5 \%$ of their BMI at mean age 24 (wave 4). In earlier studies, researchers have used varying definitions for weight maintenance ( $\pm 5 \mathrm{lbs}, \pm 3 \%$, $\pm 5 \%$ ) (Ball et al., 2002; Lindvall et al., 2013; Nafziger et al., 2007; St Jeor et al., 1995; St Jeor et al., 1997). We chose to use a permissive definition ( $\pm 5 \%$ ) to maximize the likelihood of success in weight maintenance. We also computed annual weight change for women and men as follows: mean weight at mean age 34 (wave 5) subtracted from mean weight at mean age 24 (wave 4) and divided by the exact length of follow-up, i.e. time difference between return of questionnaires.

\subsubsection{History of dieting}

In this study 'History of dieting' is conceptualized as having history of intentional weight loss from a self-report of having intentionally lost $\geq 5 \mathrm{~kg}$ at least once during one's lifetime (Keski-Rahkonen et al., 2006) at an average age of 24 (wave 4).

\subsubsection{Food and drink intake}

Continuous scores of food factors were derived from a food 
frequency questionnaire administered at mean age 24 (wave 4). The food-frequency questionnaire was modified from a previous national food-frequency questionnaire (Keskitalo et al., 2008) and covered the main food groups (cereals, rice, pasta, meat, poultry, fish, eggs, fresh and cooked vegetables, fruits, berries, milk products, yoghurt, cheese, fats, oils, sweets, and fast food) and sweet drinks (sugared soft drinks or juices). Participants evaluated how often they consumed various foods and drinks using five response categories $(1=$ never, $2=$ a couple times a month or less, $3=$ a couple times a week, $4=$ once a day, $5=$ several times a day). From a principal component analysis (Keskitalo et al., 2008), the following four factors emerged: Factor 1, 'Healthy Foods', included fresh vegetables, fruits, cooked vegetables, berries, porridge, reduced fat cheese, rice, chicken, yoghurt and fish. Factor 2, 'High Fat Foods', included fried foods, hamburgers, pizza, fried potatoes or French fries, creamy foods and salty snacks. Factor 3, 'Sweet Foods', included sweets, chocolate and sweet desserts. Factor 4, 'Meat', included sausage and meat. Sweet drinks were added as a separate, independent category.

\subsubsection{Alcohol use per month}

From the questionnaires, we calculated the monthly alcohol intake, expressed as drinks per month at mean age 24 (wave 4).

\subsubsection{Regularity of eating and eating styles}

Regularity of eating and eating styles were assessed at mean age 24 (wave 4). We used a questionnaire previously developed by us (KeskiRahkonen et al., 2007) to address regularity of eating with a question "How would you describe your regularity of eating?" using four alternatives: 'regular', 'quite regular', 'quite irregular' and 'chaotic'. Eating styles were assessed by asking our participants to choose one of four options that best characterized their overall eating style. We contrasted individuals who answered 'It is easy for me to eat about the amount I need to' with the alternatives 'I quite often eat more than I actually need' (overeating), 'I often try to restrict my eating' (restrictive eating), and 'At times, I'm on a strict diet, at others I overeat' (restricting and overeating).

\subsubsection{Disinhibited eating}

Disinhibited eating was assessed using the Bulimia subscale of the Eating Disorder Inventory (Garner, 1991; Keski-Rahkonen et al., 2005) at mean age 24 (wave 4). It was rated with a 6-point Likert scale ranging from 'Always' to 'Never', and was used as a continuous variable. We chose to use the Bulimia subscale to measure disinhibited eating because it includes binge-eating-related behaviors, which are the risk factors for weight gain and obesity. Bulimia subscale contains 7 items, with a range from 7 to 40 (Chronbach's alpha was 0.83).

\subsubsection{Daily breakfast}

The frequency of breakfast eating was assessed at mean age 24 (wave 4) by the following question: 'How often do you eat breakfast before going to school or going to work?'. The three alternative responses were 'every morning', 'a few times a week' and 'about once a week or less often'. Alternatives were dichotomized to daily vs. less frequent (Keski-Rahkonen et al., 2003).

\subsubsection{Physical activity}

A physical activity index was calculated at mean age 24 (wave 4) from the product of self-reported exercise intensity, duration (hours) and yearly frequency (days). Intensity was expressed as estimated metabolic equivalent (MET) values (work metabolic rate divided by resting metabolic rate) (Wilson, Paffenbarger Jr, Morris, \& Havlik, 1986). Adequate validity of these measures was found with respect to interviews and fitness assessments of $\mathrm{VO}_{2}$ max among these twins in adolescence (Aarnio, Winter, Peltonen, Kujala, \& Kaprio, 2002). A cardiorespiratory exercise test was performed in 48 monozygotic twin individuals from the FinnTwin16 cohort, as previously described
(Mustelin et al., 2008), and we found a reasonably strong correlation $(\mathrm{r}=0.53)$ between $\mathrm{VO}_{2}$ max and the physical activity index.

\subsubsection{Life satisfaction}

We used Allardt's four item scale for life satisfaction (Linna et al., 2013) to measure levels of interest, happiness, ease and loneliness in life at mean age 24 (wave 4). The response alternatives were scored as previously reported on a scale from 1 to 5, yielding a range of 4-20. Higher scores indicate low satisfaction. The internal consistency of the scale was good (Cronbach's alpha 0.71) (Allardt, 1973).

\subsubsection{Self-rated health}

Self-rated health was assessed at mean age 24 (wave 4) by a question 'What do you think about your current health status?' that offered five preset response alternatives: 1) Very good, 2) Fairly good, 3) Average, 4) Fairly poor or 5) Poor. Because very few responders reported their current health status as 'Fairly poor' or 'Poor', these categories were combined with 'Average' group to yield three categories in the analysis.

\subsubsection{Education}

Education level was measured at mean age 24 when participants reported that school they were graduated from (Comprehensive school, Vocational school, Vocational college, High School, Polytechnic, University). Because at mean age 24 many participants may have been currently students in Polytechnic or University and not yet graduated, we dichotomized our participants in two groups by their education level; 'education level lower than high school' and 'at least a high school education', cut-off point 12 years of education.

\subsection{Statistical analyses}

We described our continuous variables using means, standard deviations and categorical measures with cross tabulations and proportions. We used logistic regression modeling to examine the relationship of weight maintenance (vs. weight gain) and independent variables. Therefore, participants who lost $>5 \%$ of their BMI over ten years were excluded from logistic regression analyses in this study. We tested all variables for multicollinearity and excluded variables with correlation 0.6 or higher.

We built our models based on factors associated with long-term weight maintenance from earlier literature. Separate models were conducted for women and men. We tested three nested multivariable logistic regression models (Fig. 1) to find factors at mean age 24 associated with long-term weight maintenance; models accounted for an increasing number of explanatory variables:

Model 1 ('What?') included baseline BMI, food and drink intake and physical activity.

Model 2 ('What + How?') included Model 1, eating-related variables and history of dieting.

Model 3 ('What + How + Who?') included Model 1 and Model 2 in addition to education, life satisfaction and self-rated health.

All analyses were adjusted for correlated observations within twin pairs using the statistical software package Stata 12.0 (StataCorp LP, College Station, TX).

\section{Results}

\subsection{Changes in overweight and obesity over ten years}

\subsubsection{Women}

At mean age 24 (wave 4), 10.9\% ( $=268$ ) of women were overweight and $3.6 \%(n=89)$ were affected by obesity. Ten years later (mean age 34 , wave 5), the proportion of overweight women had 


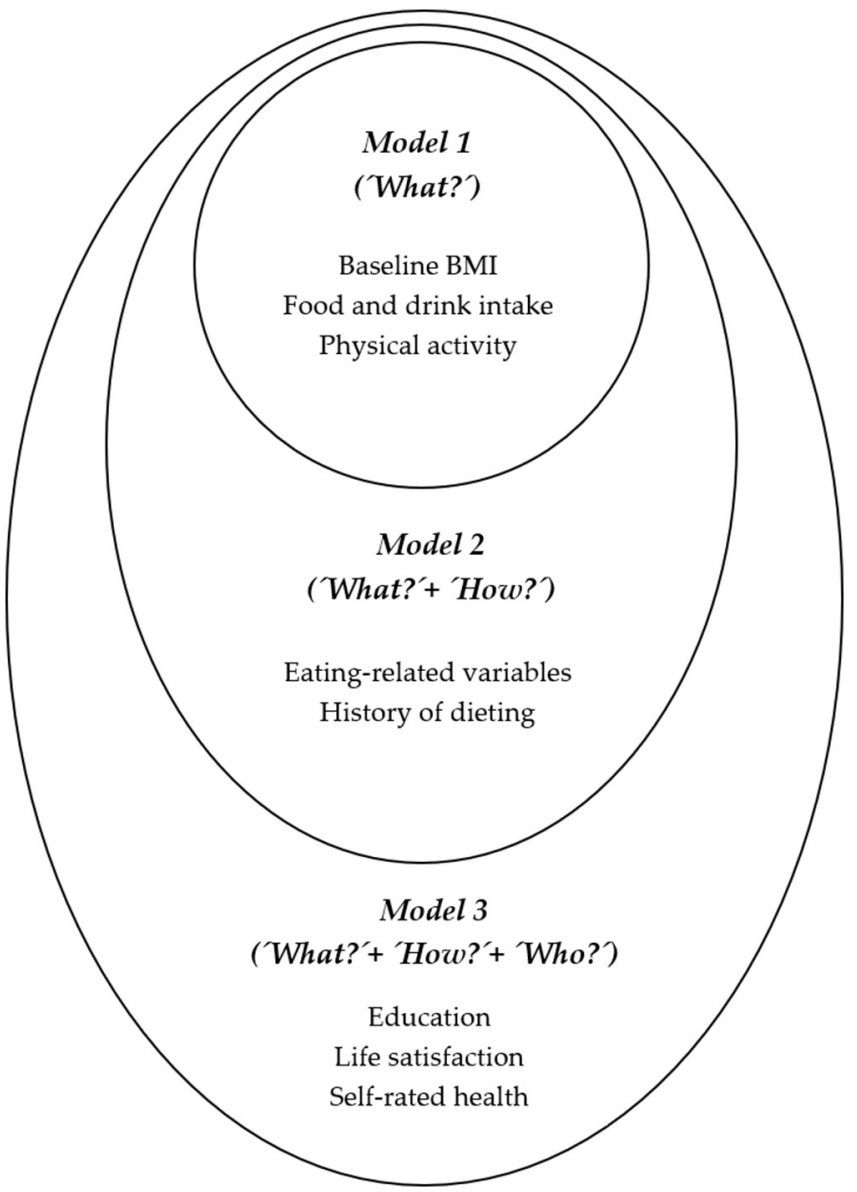

Fig. 1. Three nested multivariable logistic regression models to explain successful longterm weight maintenance.

increased to $19.1 \%(\mathrm{n}=365)$ and women with obesity to $9.1 \%$ $(\mathrm{n}=175)$, implying a three-fold increase in the prevalence of obesity among women.

\subsubsection{Men}

At mean age 24 (wave 4), 25.2\% ( $n=562)$ of men were overweight and $4.4 \%(n=99)$ were affected by obesity. Over ten years, the proportion of overweight men had increased to $42.2 \%(n=665)$ and the proportion of men with obesity to $11.4 \%(n=180)$.

\subsection{Risk of weight gain}

Women who were overweight (vs. normal weight) at mean age 24 (wave 4) had increased risk of weight gain (OR 1.6, 95\% CI 1.17-2.22). In men, being overweight (vs. normal weight) at mean age 24 (wave 4) decreased the risk of weight gain (OR 0.75 , 95\% CI 0.60-0.94) and being underweight doubled the risk of weight gain (OR 2.2, 95\% CI 1.17-4.21).

\subsection{Success in weight maintenance}

Only about a quarter of young adults maintained their weight over ten years $(28.6 \%$ of women vs. $23.0 \%$ of men, $(p=0.018)$ (Table 1$)$. Over the subsequent ten years, the majority $(63.9 \%$ of women and $73.2 \%$ of men) gained weight. Among women who gained weight, the mean weight gain was $9.2 \mathrm{~kg}$ (SD $6.3 \mathrm{~kg}$ ); among men, $10.3 \mathrm{~kg}$ (SD 6.3) (Table 4). Weight loss $>5 \%$ of BMI over the ten-year period was uncommon $(7.5 \%$ of women and $3.8 \%$ of men, $\mathrm{p}<0.001$ ) (Table 2 ).

Most of the women (72\%) who maintained their weight over ten years were normal weight, $18 \%$ were underweight and $10 \%$ were overweight or with obesity at mean age 24 (Table 3). At mean age 24, over $60 \%$ of men who maintained their weight over ten years were normal weight, $21 \%$ underweight and $33 \%$ overweight or with obesity (Table 3).

\subsection{Factors associated with successful weight maintenance}

\subsubsection{Women}

Results from all three nested models for women are presented in Table 5. In the full model (Model 3), physical activity was associated with successful weight maintenance among women, whereas sweet drinks, irregular eating, and dieting were associated with weight gain. Low satisfaction with one's life or having two or more children was also associated with weight gain (Table 5).

\subsection{2. $M e n$}

Results from all three nested models for men are presented in Table 6. In the full model, only higher baseline BMI and higher educational level predicted successful weight maintenance among men, whereas irregular eating, dieting, and smoking were associated with weight gain (Table 6).

\section{Discussion and conclusion}

Our longitudinal nationwide study suggests that weight gain rather than weight maintenance is the norm for the most of the young adults.

Table 1

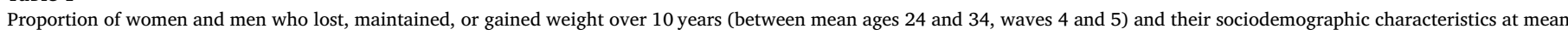
age 24 .

\begin{tabular}{|c|c|c|c|c|c|c|}
\hline & \multicolumn{3}{|c|}{ Women $(\mathrm{N}=2452)$} & \multicolumn{3}{|c|}{ Men $(N=2227)$} \\
\hline & $\begin{array}{l}\text { Losers } \\
\mathrm{n}=185\end{array}$ & $\begin{array}{l}\text { Maintainers } \\
\mathrm{n}=701\end{array}$ & $\begin{array}{l}\text { Gainers } \\
\mathrm{n}=1566\end{array}$ & $\begin{array}{l}\text { Losers } \\
\mathrm{n}=84\end{array}$ & $\begin{array}{l}\text { Maintainers } \\
\mathrm{n}=513\end{array}$ & $\begin{array}{l}\text { Gainers } \\
\mathrm{n}=1630\end{array}$ \\
\hline $\begin{array}{l}\text { High school education, } \\
\text { n (\%) }\end{array}$ & $\begin{array}{l}119 \\
(64.3)\end{array}$ & $\begin{array}{l}492 \\
(70.2)\end{array}$ & $\begin{array}{l}960 \\
(61.3)\end{array}$ & $\begin{array}{l}51 \\
(60.7)\end{array}$ & $\begin{array}{l}305 \\
(59.5)\end{array}$ & $\begin{array}{l}756 \\
(46.4)\end{array}$ \\
\hline $\begin{array}{l}\text { Married or cohabiting, } \\
\text { n (\%) }\end{array}$ & $\begin{array}{l}115 \\
(62.2)\end{array}$ & $\begin{array}{l}505 \\
(72.0)\end{array}$ & $\begin{array}{l}1073 \\
(68.5)\end{array}$ & $\begin{array}{l}42 \\
(50.0)\end{array}$ & $\begin{array}{l}329 \\
(64.1)\end{array}$ & $\begin{array}{l}971 \\
(72.4)\end{array}$ \\
\hline \multicolumn{7}{|l|}{ Parity, n (\%) } \\
\hline No children & $\begin{array}{l}154 \\
(83.2)\end{array}$ & $\begin{array}{l}619 \\
(88.3)\end{array}$ & $\begin{array}{l}1316 \\
(84.0)\end{array}$ & $\begin{array}{l}80 \\
(95.2)\end{array}$ & $\begin{array}{l}465 \\
(90.6)\end{array}$ & $\begin{array}{l}1425 \\
(87.4)\end{array}$ \\
\hline One child & $\begin{array}{l}19 \\
(10.3)\end{array}$ & $\begin{array}{l}51 \\
(7.3)\end{array}$ & $\begin{array}{l}152 \\
(9.7)\end{array}$ & $\begin{array}{l}4 \\
(4.8)\end{array}$ & $\begin{array}{l}25 \\
(4.9)\end{array}$ & $\begin{array}{l}133 \\
(8.2)\end{array}$ \\
\hline Two or more children & $\begin{array}{l}12 \\
(6.5)\end{array}$ & $\begin{array}{l}31 \\
(4.4)\end{array}$ & $\begin{array}{l}98 \\
(6.3)\end{array}$ & $\begin{array}{l}0 \\
(0)\end{array}$ & $\begin{array}{l}22 \\
(4.3)\end{array}$ & $\begin{array}{l}69 \\
(4.2)\end{array}$ \\
\hline $\begin{array}{l}\text { Urban (vs. rural), } \\
n(\%)\end{array}$ & $\begin{array}{l}171 \\
(92.4)\end{array}$ & $\begin{array}{l}615 \\
(87.7)\end{array}$ & $\begin{array}{l}1324 \\
(84.5)\end{array}$ & $\begin{array}{l}72 \\
(85.7)\end{array}$ & $\begin{array}{l}435 \\
(84.8)\end{array}$ & $\begin{array}{l}1298 \\
(79.6)\end{array}$ \\
\hline
\end{tabular}


Table 2

Proportion of women and men who lost, maintained or gained weight and their eating- and lifestyle-related characteristics at mean age 24 .

\begin{tabular}{|c|c|c|c|c|c|c|}
\hline & \multicolumn{3}{|c|}{ Women $(\mathrm{N}=2452)$} & \multicolumn{3}{|c|}{$\operatorname{Men}(\mathrm{N}=2227)$} \\
\hline & $\begin{array}{l}\text { Losers } \\
\mathrm{n}=185\end{array}$ & $\begin{array}{l}\text { Maintainers } \\
\mathrm{n}=701\end{array}$ & $\begin{array}{l}\text { Gainers } \\
\mathrm{n}=1566\end{array}$ & $\begin{array}{l}\text { Losers } \\
\mathrm{n}=84\end{array}$ & $\begin{array}{l}\text { Maintainers } \\
\mathrm{n}=513\end{array}$ & $\begin{array}{l}\text { Gainers } \\
\mathrm{n}=1630\end{array}$ \\
\hline Healthy foods ${ }^{a}$ & $2.9(0.5)$ & $2.9(0.5)$ & $2.8(0.4)$ & $2.5(0.5)$ & $2.6(0.5)$ & $2.5(0.4)$ \\
\hline High fat foods ${ }^{a}$ & $2.0(0.3)$ & $2.0(0.3)$ & $2.0(0.3)$ & $2.2(0.4)$ & $2.2(0.3)$ & $2.2(0.3)$ \\
\hline Sweet foods ${ }^{\mathrm{a}}$ & $2.5(0.5)$ & $2.6(0.5)$ & $2.6(0.5)$ & $2.3(0.5)$ & $2.4(0.5)$ & $2.4(0.5)$ \\
\hline Meat $^{\mathrm{a}}$ & $2.6(0.7)$ & $2.6(0.8)$ & $2.7(0.8)$ & $3.0(0.7)$ & $3.1(0.7)$ & $3.2(0.8)$ \\
\hline Sweet drinks ${ }^{\mathrm{a}}$ & $2.1(1.0)$ & $2.2(0.9)$ & $2.3(1.0)$ & $2.8(1.0)$ & $2.8(0.9)$ & $2.8(1.0)$ \\
\hline Alcohol use per month ${ }^{\mathrm{a}}$ & $16.4(21.4)$ & $16.4(23.8)$ & $17.2(38.2)$ & 43.9 (48.5) & $31.3(36.6)$ & $35.2(42.4)$ \\
\hline $\mathrm{MET}^{\mathrm{a}, \mathrm{c}}$ & $4.4(5.1)$ & $5.0(5.1)$ & $3.9(4.3)$ & $3.6(4.4)$ & $6.1(6.0)$ & $4.8(5.3)$ \\
\hline Daily breakfast $^{\mathrm{b}}$ & $113(7.7)$ & $451(30.7)$ & $904(60.6)$ & $37(3.4)$ & $264(24.4)$ & $782(72.2)$ \\
\hline \multicolumn{7}{|l|}{ Regularity of eating ${ }^{\mathrm{b}}$} \\
\hline Regular & $15(8.5)$ & 59 (33.5) & $102(58.0)$ & $8(3.6)$ & $67(30.3)$ & $146(66.0)$ \\
\hline Quite regular & $97(6.9)$ & $414(29.4)$ & $899(63.8)$ & $50(4.0)$ & $301(24.1)$ & 897 (71.9) \\
\hline Quite irregular & $61(9.4)$ & $158(24.5)$ & $427(66.1)$ & $20(3.3)$ & $123(20.1)$ & $468(76.6)$ \\
\hline Chaotic & $12(5.5)$ & $70(32.1)$ & $136(62.4)$ & $6(4.1)$ & $22(15.1)$ & $118(80.8)$ \\
\hline \multicolumn{7}{|l|}{ Control in eating ${ }^{\mathrm{b}}$} \\
\hline Normal eating & $83(5.9)$ & $416(29.3)$ & $920(64.8)$ & $54(3.1)$ & $385(22.5)$ & $1271(74.3)$ \\
\hline Overeating & $56(9.7)$ & $158(27.3)$ & $364(63.0)$ & $26(6.1)$ & $110(25.8)$ & $290(68.1)$ \\
\hline Restrictive & $32(10.8)$ & $82(27.6)$ & $183(61.6)$ & $2(3.1)$ & $13(20.3)$ & $49(76.6)$ \\
\hline Restrictive and overeating & $14(9.2)$ & $45(29.6)$ & $93(61.2)$ & $2(8.0)$ & $5(20.0)$ & $18(72.0)$ \\
\hline History of dieting $\geq 5 \mathrm{~kg}^{\mathrm{b}}$ & $50(11.5)$ & 99 (20.7) & $287(65.8)$ & $23(9.2)$ & $31(12.5)$ & $195(78.3)$ \\
\hline Disinhibited eating & $24(11.3)$ & $59(27.8)$ & $129(60.9)$ & $1(5.6)$ & $2(11.1)$ & $15(83.3)$ \\
\hline Smoking (vs. non-smoking) ${ }^{\mathrm{b}}$ & $51(8.4)$ & $149(24.4)$ & $410(67.2)$ & $26(3.8)$ & $124(18.2)$ & $531(78.0)$ \\
\hline Life satisfaction ${ }^{a}$ & $9.0(1.8)$ & $8.9(1.7)$ & $9.2(1.9)$ & $9.1(2.2)$ & $9.0(1.7)$ & $9.2(2.0)$ \\
\hline Self-rated health ${ }^{\mathrm{a}}$ & $1.9(0.8)$ & $1.8(0.7)$ & $1.9(0.7)$ & $2.0(0.7)$ & $1.7(0.7)$ & $1.8(0.7)$ \\
\hline
\end{tabular}

a Mean (SD)

b $\mathrm{n}(\%)$.

${ }^{\mathrm{c}}$ Metabolic equivalent of Task (MET), work metabolic rate divided by resting metabolic rate.

d Continuous score from Eating Disorder Inventory Bulimia subscale.

Table 3

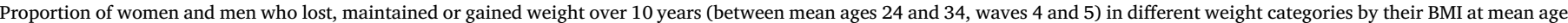
24.

\begin{tabular}{|c|c|c|c|c|c|c|}
\hline & \multicolumn{3}{|c|}{ Women $(\mathrm{N}=2452)$} & \multicolumn{3}{|c|}{$\operatorname{Men}(\mathrm{N}=2227)$} \\
\hline & $\begin{array}{l}\text { Losers } \\
\mathrm{n}=185\end{array}$ & $\begin{array}{l}\text { Maintainers } \\
\mathrm{n}=701\end{array}$ & $\begin{array}{l}\text { Gainers } \\
\mathrm{n}=1566\end{array}$ & $\begin{array}{l}\text { Losers } \\
\mathrm{n}=84\end{array}$ & $\begin{array}{l}\text { Maintainers } \\
\mathrm{n}=513\end{array}$ & $\begin{array}{l}\text { Gainers } \\
\mathrm{n}=1630\end{array}$ \\
\hline \multicolumn{7}{|l|}{ BMI categories $^{\mathrm{a}}$} \\
\hline Underweight, $\mathrm{n}(\%)$ & $\begin{array}{l}10 \\
(5.4)\end{array}$ & $\begin{array}{l}124 \\
(17.7)\end{array}$ & $\begin{array}{l}314 \\
(20.1)\end{array}$ & $\begin{array}{l}0 \\
(0)\end{array}$ & $\begin{array}{l}11 \\
(2.1)\end{array}$ & $\begin{array}{l}82 \\
(5.0)\end{array}$ \\
\hline Normal weight, n (\%) & $\begin{array}{l}125 \\
(67.6)\end{array}$ & $\begin{array}{l}504 \\
(71.9)\end{array}$ & $\begin{array}{l}1018 \\
(65.0)\end{array}$ & $\begin{array}{l}29 \\
(34.5)\end{array}$ & $\begin{array}{l}332 \\
(64.7)\end{array}$ & $\begin{array}{l}1115 \\
(68.4)\end{array}$ \\
\hline Overweight, n (\%) & $\begin{array}{l}34 \\
(18.4)\end{array}$ & $\begin{array}{l}55 \\
(7.8)\end{array}$ & $\begin{array}{l}179 \\
(11.4)\end{array}$ & $\begin{array}{l}35 \\
(41.7)\end{array}$ & $\begin{array}{l}149 \\
(29.0)\end{array}$ & $\begin{array}{l}378 \\
(23.2)\end{array}$ \\
\hline Obesity, n (\%) & $\begin{array}{l}16 \\
(8.6)\end{array}$ & $\begin{array}{l}18 \\
(2.6)\end{array}$ & $\begin{array}{l}55 \\
(3.5)\end{array}$ & $\begin{array}{l}20 \\
(23.8)\end{array}$ & $\begin{array}{l}21 \\
(4.1)\end{array}$ & $\begin{array}{l}55 \\
(3.4)\end{array}$ \\
\hline
\end{tabular}

a BMI categories: underweight $<19.5 \mathrm{~kg} / \mathrm{m}^{2}$; normal weight $19.5-24.9 \mathrm{~kg} / \mathrm{m}^{2}$; overweight $25-29.9 \mathrm{~kg} / \mathrm{m}^{2} ;$ obesity $>29.9 \mathrm{~kg} / \mathrm{m}^{2}$.

In our setting, $29 \%$ of women vs. $23 \%$ of men maintained their weight over ten years. Dieting and irregular eating predicted weight gain in both sexes. Among women, sweet drinks and having children predicted weight gain whereas physical activity predicted weight maintenance. Among men, smoking predicted weight gain whereas being highly educated predicted weight maintenance. Finally, men with higher baseline BMI were also less likely to gain weight than those with lower BMI.

Our study documents an important period during young adulthood when maintaining a normal weight becomes a complex challenge for the majority. Of our participants, only about a quarter was able to maintain their weight over ten years. This means that in our current living environment, long-term weight maintenance is not an easily achievable goal for most young adults. Weight maintenance is difficult to compare across studies because of varying definitions ( \pm 5lbs, \pm $3 \%, \pm 5 \%$ ), of different age groups and follow-up periods (Ball et al., 2002; Brown et al., 2016; Lindvall et al., 2013; Nafziger et al., 2007; St
Jeor et al., 1995; St Jeor et al., 1997). We used a permissive definition $( \pm 5 \%$ ) that maximizes the likelihood of success in weight maintenance. Despite this, the proportion of weight maintainers was lower in our study than in other long-term surveys conducted to date (Ball et al., 2002; Nafziger et al., 2007). This, in turn, is worrisome, because net weight loss was rare $(7.5 \%$ of women vs. $3.8 \%$ of men) and the average annual weight gain of $1.0 \mathrm{~kg}$ for men and $0.9 \mathrm{~kg}$ for women in our study is among the highest documented in Western countries (Chiriboga et al., 2008; Nafziger et al., 2007; St Jeor et al., 1995). Further, on average, adult women are two and men three BMI units heavier in Finland compared to global mean BMIs (NCD Risk Factor Collaboration (NCD-RisC), 2016; Lahti-Koski, Harald, Saarni, Peltonen, \& Mannisto, 2012).

Two key predictors of weight gain were shared by both men and women: irregular eating and dieting. The association of regular eating with weight maintenance has also been observed in other settings (Karfopoulou et al., 2017). Dieting has previously been found to predict 
Table 4

Weight-related characteristics at mean age 24 of women and men who lost, maintained or gained weight over ten years (between mean ages 24 and 34 , waves 4 and 5 ).

\begin{tabular}{|c|c|c|c|c|c|c|}
\hline & \multicolumn{3}{|c|}{ Women $(\mathrm{N}=2452)$} & \multicolumn{3}{|c|}{ Men $(\mathrm{N}=2227)$} \\
\hline & $\begin{array}{l}\text { Losers } \\
\mathrm{n}=185\end{array}$ & $\begin{array}{l}\text { Maintainers } \\
\mathrm{n}=701\end{array}$ & $\begin{array}{l}\text { Gainers } \\
\mathrm{n}=1566\end{array}$ & $\begin{array}{l}\text { Losers } \\
\mathrm{n}=84\end{array}$ & $\begin{array}{l}\text { Maintainers } \\
\mathrm{n}=513\end{array}$ & $\begin{array}{l}\text { Gainers } \\
\mathrm{n}=1630\end{array}$ \\
\hline Height $(\mathrm{cm})$, mean (SD) & $166.3(6.4)$ & $\begin{array}{l}166.3 \\
(5.8)\end{array}$ & $165.6(5.7)$ & $179.8(6.7)$ & $\begin{array}{l}179.9 \\
(6.0)\end{array}$ & $179.2(6.7)$ \\
\hline Weight (kg), mean (SD) & $66.0(10.7)$ & $\begin{array}{l}60.4 \\
(9.2)\end{array}$ & $60.6(10.4)$ & $88.0(15.6)$ & $\begin{array}{l}78.4 \\
(10.9)\end{array}$ & $76.2(11.5)$ \\
\hline BMI $\left(\mathrm{kg} / \mathrm{m}^{2}\right)$, mean (SD) & $\begin{array}{l}23.9 \\
(3.7)\end{array}$ & $\begin{array}{l}21.8 \\
(3.1)\end{array}$ & $\begin{array}{l}22.1 \\
(3.5)\end{array}$ & $27.2(4.4)$ & $\begin{array}{l}24.2 \\
(2.9)\end{array}$ & $\begin{array}{l}23.7 \\
(3.0)\end{array}$ \\
\hline Waist circumference $(\mathrm{cm})$, mean (SD) & $\begin{array}{l}78.7 \\
(9.7)\end{array}$ & $\begin{array}{l}73.4 \\
(7.9)\end{array}$ & $\begin{array}{l}74.7 \\
(9.6)\end{array}$ & $92.9(11.5)$ & $\begin{array}{l}85.3 \\
(8.8)\end{array}$ & $\begin{array}{l}85.1 \\
(9.1)\end{array}$ \\
\hline Waist circumference change over $10 \mathrm{y}$, mean (SD) & $\begin{array}{l}-2.4 \\
(8.2)\end{array}$ & $\begin{array}{l}3.3 \\
(6.9)\end{array}$ & $\begin{array}{l}10.0 \\
(8.3)\end{array}$ & $-4.3(9.7)$ & $\begin{array}{l}3.0 \\
(5.2)\end{array}$ & $\begin{array}{l}10.1 \\
(7.4)\end{array}$ \\
\hline BMI change over $10 \mathrm{y}\left(\mathrm{kg} / \mathrm{m}^{2}\right)$, mean (SD) & $\begin{array}{l}-2.2 \\
(1.4)\end{array}$ & $\begin{array}{l}0.2 \\
(0.6)\end{array}$ & $\begin{array}{l}3.4 \\
(2.3)\end{array}$ & $-2.9(2.1)$ & $\begin{array}{l}0.3 \\
(0.6)\end{array}$ & $\begin{array}{l}3.2 \\
(1.9)\end{array}$ \\
\hline Weight change over 10 y $(\mathrm{kg})$, mean (SD) & $\begin{array}{l}-5.6 \\
(3.8)\end{array}$ & $\begin{array}{l}0.4 \\
(1.8)\end{array}$ & $\begin{array}{l}9.2 \\
(6.3)\end{array}$ & $\begin{array}{l}-9.4 \\
(7.3)\end{array}$ & $\begin{array}{l}1.0 \\
(2.3)\end{array}$ & $\begin{array}{l}10.3 \\
(6.3)\end{array}$ \\
\hline
\end{tabular}

Table 5

Factors at mean age 24 associated with weight maintenance (vs. weight gain) over 10 years in women: odds ratios (OR) from multivariable logistic regression models.

\begin{tabular}{|c|c|c|c|c|c|c|}
\hline & \multicolumn{2}{|c|}{$\begin{array}{l}\text { Model } \\
\text { What? }\end{array}$} & \multicolumn{2}{|c|}{$\begin{array}{l}\text { Model } \\
\text { How? }\end{array}$} & \multicolumn{2}{|c|}{$\begin{array}{l}\text { Model } \\
\text { Who? }\end{array}$} \\
\hline & OR & $95 \% \mathrm{CI}$ & OR & $95 \% \mathrm{CI}$ & OR & $95 \% \mathrm{CI}$ \\
\hline $\mathrm{BMI}^{\mathrm{a}}$ at mean age 24 & 0.95 & $0.82-1.08$ & 0.97 & $0.83-1.14$ & 1.00 & $0.85-1.17$ \\
\hline Healthy foods & 1.08 & $0.93-1.26$ & 1.06 & $0.91-1.25$ & 1.05 & $0.89-1.23$ \\
\hline High fat foods ${ }^{b}$ & 1.00 & $0.84-1.18$ & 1.01 & $0.84-1.20$ & 1.00 & $0.84-1.20$ \\
\hline Sweet foods ${ }^{b}$ & 1.06 & $0.92-1.21$ & 1.07 & $0.93-1.25$ & 1.06 & $0.92-1.23$ \\
\hline Meat $^{\mathrm{b}}$ & 1.05 & $0.92-1.21$ & 1.05 & $0.91-1.21$ & 1.07 & $0.93-1.24$ \\
\hline Sweet drinks & 0.79 & $0.68-0.92$ & 0.78 & $0.66-0.91$ & 0.79 & $0.67-0.93$ \\
\hline $\begin{array}{l}\text { Alcohol use per } \\
\text { month }\end{array}$ & 1.02 & $0.90-1.17$ & 1.03 & $0.90-1.17$ & 1.02 & $0.89-1.17$ \\
\hline MET $^{\mathrm{c}}$ & 1.36 & $1.18-1.57$ & 1.37 & $1.19-1.59$ & 1.35 & $1.16-1.57$ \\
\hline Daily breakfast & & & 1.09 & $0.82-1.45$ & 1.06 & $0.80-1.41$ \\
\hline \multicolumn{7}{|l|}{ Regularity of eating } \\
\hline Regular & & & 1.0 & (Reference) & 1.0 & (Reference) \\
\hline Quite regular & & & 0.63 & $0.38-1.03$ & 0.63 & $0.38-1.04$ \\
\hline Quite irregular & & & 0.53 & $0.30-0.92$ & 0.55 & $0.31-0.97$ \\
\hline Chaotic & & & 1.03 & $0.51-2.07$ & 1.14 & $0.56-2.34$ \\
\hline \multicolumn{7}{|l|}{ Control in eating } \\
\hline Normal eating & & & 1.00 & (Reference) & 1.00 & (Reference) \\
\hline Overeating & & & 1.30 & $0.92-1.85$ & 1.30 & $0.91-1.85$ \\
\hline Restrictive & & & 1.14 & $0.72-1.80$ & 1.13 & $0.72-1.80$ \\
\hline $\begin{array}{l}\text { Restrictive and } \\
\text { overeating }\end{array}$ & & & 1.80 & $0.95-3.41$ & 1.73 & $0.91-3.30$ \\
\hline $\begin{array}{l}\text { History of dieting } \\
\quad \geq 5 \mathrm{~kg}\end{array}$ & & & 0.58 & $0.39-0.86$ & 0.59 & $0.39-0.88$ \\
\hline Disinhibited eating ${ }^{\mathrm{d}}$ & & & 0.98 & $0.85-1.13$ & 1.00 & $0.86-1.17$ \\
\hline $\begin{array}{l}\text { Education, } \\
\geq 12 \text { years (vs. } \\
\text { less) }\end{array}$ & & & & & 1.17 & $0.84-1.63$ \\
\hline No children & & & & & 1.00 & (Reference) \\
\hline One child & & & & & 0.93 & $0.55-1.59$ \\
\hline$\geq 2$ children & & & & & 0.30 & $0.11-0.84$ \\
\hline $\begin{array}{l}\text { Smoking (vs. non- } \\
\text { smoking) }\end{array}$ & & & & & 0.87 & $0.65-1.17$ \\
\hline $\begin{array}{l}\text { Low life } \\
\quad \text { satisfaction }^{\mathrm{e}}\end{array}$ & & & & & 0.83 & $0.71-0.97$ \\
\hline Self-rated health & & & & & 1.07 & $0.85-1.34$ \\
\hline
\end{tabular}

Boldface indicates statistical significance.

Logistic regression models, corrected for cluster sampling.

Continuous scores are standardized.

${ }^{a}$ BMI $\left(\mathrm{kg} / \mathrm{m}^{2}\right)$.

${ }^{\mathrm{b}}$ Continuous scores derived from a food frequency questionnaire.

${ }^{c}$ Metabolic equivalent of Task (MET), work metabolic rate divided by resting metabolic rate.

${ }^{\mathrm{d}}$ Continuous score from Eating Disorder Inventory Bulimia subscale.

e Continuous score derived from Allardt's life satisfaction questionnaire.
Table 6

Factors at mean age 24 associated with weight maintenance (vs. weight gain) over 10 years in men: odds ratios (OR) from multivariable logistic regression models.

\begin{tabular}{|c|c|c|c|c|c|c|}
\hline & \multicolumn{2}{|c|}{$\begin{array}{l}\text { Model } \\
\text { What? }\end{array}$} & \multicolumn{2}{|c|}{$\begin{array}{l}\text { Model } \\
\text { How? }\end{array}$} & \multicolumn{2}{|c|}{$\begin{array}{l}\text { Model } \\
\text { Who? }\end{array}$} \\
\hline & OR & $95 \% \mathrm{CI}$ & OR & $95 \% \mathrm{CI}$ & OR & $95 \% \mathrm{CI}$ \\
\hline $\mathrm{BMI}^{\mathrm{a}}$ at mean age 24 & 1.20 & $1.01-1.42$ & 1.35 & $1.12-1.62$ & 1.39 & $1.14-1.70$ \\
\hline Healthy foods ${ }^{\mathrm{b}}$ & 1.17 & $0.99-1.38$ & 1.12 & $0.94-1.33$ & 1.04 & $0.86-1.24$ \\
\hline High fat foods ${ }^{\mathrm{b}}$ & 0.86 & $0.73-1.02$ & 0.86 & $0.74-1.04$ & 0.90 & $0.76-1.07$ \\
\hline Sweet foods ${ }^{b}$ & 0.96 & $0.82-1.13$ & 0.97 & $0.83-1.14$ & 0.95 & $0.81-1.11$ \\
\hline Meat $^{\mathrm{b}}$ & 0.85 & $0.72-1.00$ & 0.82 & $0.69-0.98$ & 0.85 & $0.72-1.02$ \\
\hline Sweet drinks & 1.13 & $0.97-1.32$ & 1.12 & $0.95-1.31$ & 1.14 & $0.97-1.34$ \\
\hline $\begin{array}{l}\text { Alcohol use per } \\
\text { month }\end{array}$ & 0.96 & $0.82-1.13$ & 0.97 & $0.82-1.14$ & 0.99 & $0.83-1.18$ \\
\hline MET $^{\mathrm{c}}$ & 1.16 & $1.01-1.34$ & 1.14 & $0.99-1.32$ & 1.12 & $0.96-1.31$ \\
\hline Daily breakfast & & & 1.02 & $0.74-1.41$ & 0.97 & $0.70-1.34$ \\
\hline \multicolumn{7}{|l|}{ Regularity of eating } \\
\hline Regular & & & 1.00 & (Reference) & 1.00 & (Reference) \\
\hline Quite regular & & & 0.57 & $0.36-0.91$ & 0.58 & $0.36-0.92$ \\
\hline Quite irregular & & & 0.56 & $0.33-0.95$ & 0.56 & $0.33-0.97$ \\
\hline Chaotic & & & 0.43 & $0.19-0.97$ & 0.47 & $0.21-1.06$ \\
\hline \multicolumn{7}{|l|}{ Control in eating } \\
\hline Normal eating & & & 1.00 & (Reference) & 1.00 & (Reference) \\
\hline Overeating & & & 0.99 & $0.67-1.46$ & 0.99 & $0.66-1.47$ \\
\hline Restrictive & & & 0.91 & $0.31-2.70$ & 0.83 & $0.28-2.44$ \\
\hline $\begin{array}{c}\text { Restrictive and } \\
\text { overeating }\end{array}$ & & & 3.40 & $0.79-14.44$ & 2.84 & $0.61-13.22$ \\
\hline $\begin{array}{l}\text { History of dieting } \\
\quad \geq 5 \mathrm{~kg}\end{array}$ & & & 0.30 & $0.16-0.57$ & 0.31 & $0.16-0.60$ \\
\hline Disinhibited eating $^{\mathrm{d}}$ & & & 0.95 & $0.75-1.20$ & 0.96 & $0.75-1.23$ \\
\hline $\begin{array}{l}\text { Education, } \\
\geq 12 \text { years (vs. } \\
\text { less) }\end{array}$ & & & & & 1.62 & $1.17-2.23$ \\
\hline No children & & & & & 1.00 & (Reference) \\
\hline One child & & & & & 0.74 & $0.37-1.47$ \\
\hline$\geq 2$ children & & & & & 0.99 & $0.36-2.67$ \\
\hline $\begin{array}{l}\text { Smoking (vs. non- } \\
\text { smoking) }\end{array}$ & & & & & 0.71 & $0.52-0.97$ \\
\hline $\begin{array}{l}\text { Low life } \\
\quad \text { satisfaction }^{\mathrm{e}}\end{array}$ & & & & & 0.92 & $0.78-1.10$ \\
\hline Self-rated health & & & & & 1.05 & $0.82-1.34$ \\
\hline
\end{tabular}

Boldface indicates statistical significance.

Logistic regression models, corrected for cluster sampling.

Continuous scores are standardized.

${ }^{\mathrm{a}}$ BMI $\left(\mathrm{kg} / \mathrm{m}^{2}\right)$.

${ }^{\mathrm{b}}$ Continuous scores derived from a food frequency questionnaire.

${ }^{\mathrm{c}}$ Metabolic equivalent of Task (MET), work metabolic rate divided by resting metabolic rate.

${ }^{\mathrm{d}}$ Continuous score from Eating Disorder Inventory Bulimia subscale.

${ }^{\mathrm{e}}$ Continuous score derived from Allardt's life satisfaction questionnaire. 
weight gain in this dataset (Pietilainen et al., 2012) and elsewhere (Brown et al., 2016; Dulloo et al., 2012; Logel et al., 2015; St Jeor et al., 1995). However, it is important to note that dieting may also simply reflect individual's underlying vulnerability to weight gain (Lowe, 2015). Also, biological consequences of dieting can complicate eating behavior (Benton \& Young, 2017); for example, the levels of the hunger-inducing hormone ghrelin remain increased for at least a year after weight loss (Iepsen, Lundgren, Holst, Madsbad, \& Torekov, 2016).

Physical activity and a healthy diet are the cornerstones of obesity prevention (Anon, 2000; Zamora, Gordon-Larsen, Jacobs Jr, \& Popkin, 2010). In our study, physical activity was associated with successful weight maintenance among women; among men, the effect was in the same direction but not statistically significant in the final model. In either sex, directly diet-related food factors were not significant predictors of weight maintenance. However, sweet drinks were associated with weight gain in women. This is in line with a meta-analysis showing that one daily sugar-sweetened beverage increases weight $0.12 \mathrm{~kg}$ per year among adults (Malik et al., 2013).

In this study higher education was associated with successful weight maintenance in men, but not women. The difference in education level at baseline between women and men may explain this finding; women were more educated than men $(\mathrm{p}<0.0001)$. Despite the fact that most factors associated with long-term successful weight maintenance were sex-specific, the effects for men and women were generally in the same direction and thereby not discussed in more details.

\subsection{Limitations and strengths}

Our study was limited in several ways. Firstly, weights were selfreported but in a subsample of our study self-reported weight was highly correlated with expert-measured weight (Saarni et al., 2009). Also, other researchers have stated that self-reported height and weight data are valid for identifying relationships in epidemiological studies (Spencer, Appleby, Davey, \& Key, 2002). Therefore, assuming that a tendency to underreport is rather stable, the reported change in weight should be close to the true change.

Secondly, most of the key confounders were measured only at mean age 24, precluding accounting for change or maintenance of these health behaviors during the intervening ten-year follow-up. Weights were measured only at mean ages 24 and 34, obstructing participants' weight fluctuation throughout the 10-year period. Also, based on the questionnaire, we were not able to clarify if a respondent had been pregnant recently prior to the second assessment period. Dietary information was based on a food frequency questionnaire at mean age 24 . We were unable to assess the stability of the intake patterns. However, overweight and obese individuals tend to underestimate their food intake (Murakami \& Livingstone, 2016): this might have biased our results towards the null. Yet, other prospective studies have also found that baseline food intake is a poor long-term predictor of weight change (Boggs et al., 2011).

We also experienced a modest loss to follow-up; compared to other studies, the loss was relatively small. However, because men with a history of dieting at baseline were more likely to drop out, and both women and men with higher education were more likely to respond, attrition may have increased the proportion of weight-maintainers in our sample; it is unlikely that we have underestimated the proportion of those who gained weight. Because of the large proportion of normal weight individuals at baseline, the predictors of successful weight maintenance observed in this study may not apply to populations with higher prevalence of overweight and obesity.

We believe that the weaknesses outlined above were counterbalanced by several strengths. Our study was nationwide, populationbased, and it comprised both women and men with excellent participation rates. Our follow-up time was ten years, sufficient to address meaningful weight change during young adulthood. Finally, the last wave of data collection took place recently: thus, our findings are relevant for young adults today. To our knowledge, there are no other nationwide longitudinal surveys that are informative about factors that promote or inhibit weight maintenance.

\section{Conclusion}

Our study documents an important period during young adulthood when maintaining a normal weight becomes a complex challenge for the majority. Only a quarter of young adults maintain their weight over ten years. Eating regularly and having no history of dieting were significant factors for successful weight maintenance in both women and men.

\section{References}

Aarnio, M., Winter, T., Peltonen, J., Kujala, U. M., \& Kaprio, J. (2002 Jun). Stability of leisure-time physical activity during adolescence-A longitudinal study among 16-, 17- and 18-year-old Finnish youth. Scandinavian Journal of Medicine \& Science in Sports, 12(3), 179-185.

Adams, K. F., Leitzmann, M. F., Ballard-Barbash, R., Albanes, D., Harris, T. B., Hollenbeck, A., et al. (2014 Jan 15). Body mass and weight change in adults in relation to mortality risk. American Journal of Epidemiology, 179(2), 135-144.

Allardt, E. (1973). About dimension of welfare: An explanatory analysis of the comparative Scandinavian survey. University of Helsinki research group of comparative sociology research report 1. Helsinki, Finland: University of Helsinki.

Anon (2000). Obesity: preventing and managing the global epidemic. Report of a WHO consultation. World Health Organization Technical Report Series, 894(i-xii), 1-253.

Arabshahi, S., Lahmann, P. H., Williams, G. M., \& van der Pols, J. C. (2014 Mar). Predictors of change in weight and waist circumference: 15-year longitudinal study in Australian adults. European Journal of Clinical Nutrition, 68(3), 309-315.

Ball, K., Brown, W., \& Crawford, D. (2002 Dec). Who does not gain weight? Prevalence and predictors of weight maintenance in young women. International Journal of Obesity and Related Metabolic Disorders, 26(12), 1570-1578.

Benton, D., \& Young, H. A. (2017 Sep). Reducing calorie intake may not help you lose body weight. Perspectives on Psychological Science, 12(5), 703-714.

Boggs, D. A., Palmer, J. R., Spiegelman, D., Stampfer, M. J., Adams-Campbell, L. L., \& Rosenberg, L. (2011 Jul). Dietary patterns and 14-y weight gain in African American women. The American Journal of Clinical Nutrition, 94(1), 86-94.

Brown, W. J., Kabir, E., Clark, B. K., \& Gomersall, S. R. (2016 Dec). Maintaining a healthy BMI: Data from a 16-year study of young Australian women. American Journal of Preventive Medicine, 51(6), e165-e178.

Chiriboga, D. E., Ma, Y., Li, W., Olendzki, B. C., Pagoto, S. L., Merriam, P. A., et al. (2008 Jan). Gender differences in predictors of body weight and body weight change in healthy adults. Obesity (Silver Spring), 16(1), 137-145.

Dulloo, A. G., Jacquet, J., \& Montani, J. P. (2012 Aug). How dieting makes some fatter: From a perspective of human body composition autoregulation. The Proceedings of the Nutrition Society, 71(3), 379-389.

Dutton, G. R., Kim, Y., Jacobs, D. R., Jr., Li, X., Loria, C. M., Reis, J. P., et al. (2016 Sep). 25-year weight gain in a racially balanced sample of U.S. adults: The CARDIA study. Obesity (Silver Spring), 24(9), 1962-1968.

Elfhag, K., \& Rossner, S. (2005 Feb). Who succeeds in maintaining weight loss? A conceptual review of factors associated with weight loss maintenance and weight regain. Obesity Reviews, 6(1), 67-85.

Garner, D. M. (1991). In F. L. Odessa (Ed.). Eating disorder inventory 2, professional manual. Psychological Assessment Resources.

Gordon-Larsen, P., Boone-Heinonen, J., Sidney, S., Sternfeld, B., Jacobs, D. R., Jr., \& Lewis, C. E. (2009 Jul 13). Active commuting and cardiovascular disease risk: The CARDIA study. Archives of Internal Medicine, 169(13), 1216-1223.

Hankinson, A. L., Daviglus, M. L., Bouchard, C., Carnethon, M., Lewis, C. E., Schreiner, P. J., et al. (2010 Dec 15). Maintaining a high physical activity level over 20 years and weight gain. JAMA, 304(23), 2603-2610.

Iepsen, E. W., Lundgren, J., Holst, J. J., Madsbad, S., \& Torekov, S. S. (2016 Jun). Successful weight loss maintenance includes long-term increased meal responses of GLP-1 and PYY3-36. European Journal of Endocrinology, 174(6), 775-784.

Kahn, H. S., \& Williamson, D. F. (1990 Dec). The contributions of income, education and changing marital status to weight change among US men. International Journal of Obesity, 14(12), 1057-1068.

Kaprio, J. (2013 Feb). The Finnish twin cohort study: An update. Twin Research and Human Genetics, 16(1), 157-162.

Kaprio, J., Pulkkinen, L., \& Rose, R. J. (2002 Oct). Genetic and environmental factors in health-related behaviors: Studies on Finnish twins and twin families. Twin Research, 5(5), 366-371.

Karfopoulou, E., Brikou, D., Mamalaki, E., Bersimis, F., Anastasiou, C. A., Hill, J. O., et al. (2017 Apr). Dietary patterns in weight loss maintenance: Results from the MedWeight study. European Journal of Nutrition, 56(3), 991-1002.

Kärkkäinen, U., Mustelin, L., Raevuori, A., Kaprio, J., \& Keski-Rahkonen, A. (2016 Apr) Ideals versus reality: Are weight ideals associated with weight change in the population? Obesity (Silver Spring), 24(4), 947-953.

Keski-Rahkonen, A., Kaprio, J., Rissanen, A., Virkkunen, M., \& Rose, R. J. (2003 Jul). Breakfast skipping and health-compromising behaviors in adolescents and adults. European Journal of Clinical Nutrition, 57(7), 842-853. 
Keski-Rahkonen, A., Bulik, C. M., Neale, B. M., Rose, R. J., Rissanen, A., \& Kaprio, J. (2005 Apr). Body dissatisfaction and drive for thinness in young adult twins. The International Journal of Eating Disorders, 37(3), 188-199.

Keski-Rahkonen, A., Sihvola, E., Raevuori, A., Kaukoranta, J., Bulik, C. M., Hoek, H. W., et al. (2006 Dec). Reliability of self-reported eating disorders: Optimizing population screening. The International Journal of Eating Disorders, 39(8), 754-762.

Keski-Rahkonen, A., Bulik, C. M., Pietilainen, K. H., Rose, R. J., Kaprio, J., \& Rissanen, A. (2007 Jul). Eating styles, overweight and obesity in young adult twins. European Journal of Clinical Nutrition, 61(7), 822-829.

Keskitalo, K., Silventoinen, K., Tuorila, H., Perola, M., Pietilainen, K. H., Rissanen, A., et al. (2008 Jan 28). Genetic and environmental contributions to food use patterns of young adult twins. Physiology \& Behavior, 93(1-2), 235-242.

Lahti-Koski, M., Harald, K., Saarni, S. E., Peltonen, M., \& Mannisto, S. (2012 Feb). Changes in body mass index and measures of abdominal obesity in Finnish adults between 1992 and 2007, the National FINRISK Study. Clinical Obesity, 2(1-2), 57-63.

Lindvall, K., Jenkins, P., Emmelin, M., Scribani, M., Norberg, M., Larsson, C., et al. (2013 Jul 15). Primary weight maintenance: an observational study exploring candidate variables for intervention. Nutrition Journal, 12 (97-2891-12-97).

Linna, M. S., Kaprio, J., Raevuori, A., Sihvola, E., Keski-Rahkonen, A., \& Rissanen, A. (2013 Mar 16). Body mass index and subjective well-being in young adults: a twin population study. BMC Public Health, 13 (231-2458-13-231).

Logel, C., Stinson, D. A., \& Brochu, P. M. (2015). Weight loss is not the answer: A wellbeing solution to the ? Obesity problem? Social and Personality Psychology Compass, 9(12), 678-695.

Lowe, M. R. (2015 Feb). Dieting: Proxy or cause of future weight gain? Obesity Reviews, 16(Suppl. 1), 19-24.

Malik, V. S., Pan, A., Willett, W. C., \& Hu, F. B. (2013 Oct). Sugar-sweetened beverages and weight gain in children and adults: A systematic review and meta-analysis. The American Journal of Clinical Nutrition, 98(4), 1084-1102.

Murakami, K., \& Livingstone, M. B. (2016 Jan 28). Prevalence and characteristics of misreporting of energy intake in US children and adolescents: National Health and Nutrition Examination Survey (NHANES) 2003-2012. The British Journal of Nutrition, 115(2), 294-304.

Mustelin, L., Pietilainen, K. H., Rissanen, A., Sovijarvi, A. R., Piirila, P., Naukkarinen, J., et al. (2008 Jul). Acquired obesity and poor physical fitness impair expression of genes of mitochondrial oxidative phosphorylation in monozygotic twins discordant for obesity. American Journal of Physiology. Endocrinology and Metabolism, 295(1), E148-54.

Nafziger, A. N., Lindvall, K., Norberg, M., Stenlund, H., Wall, S., Jenkins, P. L., et al. (2007 Jun 12). Who is maintaining weight in a middle-aged population in Sweden? A longitudinal analysis over 10 years. BMC Public Health, 7, 108.

NCD Risk Factor Collaboration (NCD-RisC). (2016 Apr 2). Trends in adult body-mass index in 200 countries from 1975 to 2014: A pooled analysis of 1698 populationbased measurement studies with 19.2 million participants. Lancet, 387(10026), 1377-1396.

Pereira, M. A., Kartashov, A. I., Ebbeling, C. B., Van Horn, L., Slattery, M. L., Jacobs, D. R.,
Jr., et al. (2005). Fast-food habits, weight gain, and insulin resistance (the CARDIA study): 15-year prospective analysis. Lancet, 365(9453), 36-42 Jan 1-7.

Pietilainen, K. H., Saarni, S. E., Kaprio, J., \& Rissanen, A. (2012 Mar). Does dieting make you fat? A twin study. International Journal of Obesity, 36(3), 456-464.

Powell, L. H., Calvin, J. E., 3rd, \& Calvin, J. E., Jr. (2007 Apr). Effective obesity treatments. The American Psychologist, 62(3), 234-246.

Ramage, S., Farmer, A., Eccles, K. A., \& McCargar, L. (2014 Jan). Healthy strategies for successful weight loss and weight maintenance: A systematic review. Applied Physiology, Nutrition, and Metabolism, 39(1), 1-20.

Robertson, C., Avenell, A., Boachie, C., Stewart, F., Archibald, D., Douglas, F., et al. (2016 Jan-Feb). Should weight loss and maintenance programmes be designed differently for men? A systematic review of long-term randomised controlled trials presenting data for men and women: The ROMEO project. Obesity Research \& Clinical Practice, 10(1), 70-84.

Saarni, S. E., Pietilainen, K., Kantonen, S., Rissanen, A., \& Kaprio, J. (2009 Feb). Association of smoking in adolescence with abdominal obesity in adulthood: A follow-up study of 5 birth cohorts of Finnish twins. American Journal of Public Health, 99(2), 348-354.

Schmitz, K. H., Jacobs, D. R., Jr., Leon, A. S., Schreiner, P. J., \& Sternfeld, B. (2000 Nov) Physical activity and body weight: Associations over ten years in the CARDIA study. Coronary Artery Risk Development in Young Adults. International Journal of Obesity and Related Metabolic Disorders, 24(11), 1475-1487.

Spencer, E. A., Appleby, P. N., Davey, G. K., \& Key, T. J. (2002 Aug). Validity of selfreported height and weight in 4808 EPIC-Oxford participants. Public Health Nutrition, 5(4), 561-565.

St Jeor, S. T., Brunner, R. L., Harrington, M. E., Scott, B. J., Cutter, G. R., Brownell, K. D., et al. (1995 Sep). Who are the weight maintainers? Obesity Research, 2(Suppl. 3), 249s-259s.

St Jeor, S. T., Brunner, R. L., Harrington, M. E., Scott, B. J., Daugherty, S. A., Cutter, G. R., et al. (1997 May). A classification system to evaluate weight maintainers, gainers, and losers. Journal of the American Dietetic Association, 97(5), 481-488.

Stroebele-Benschop, N., Machado, A. D., Milan, F. M. P., Wössner, C., Soz, D., \& Bischoff, S. (2013). Gender differences in the outcome of obesity treatments and weight loss maintenance - a systematic review. Journal of Obesity and Weight Loss Therapy, 3(176).

Thompson, J. L. (2008 Sep). Obesity and consequent health risks: Is prevention realistic and achievable? Archives of Disease in Childhood, 93(9), 722-724.

Wilson, P. W., Paffenbarger, R. S., Jr., Morris, J. N., \& Havlik, R. J. (1986 Jun). Assessment methods for physical activity and physical fitness in population studies: Report of a NHLBI workshop. American Heart Journal, 111(6), 1177-1192.

Wing, R. R., \& Phelan, S. (2005 Jul). Long-term weight loss maintenance. The American Journal of Clinical Nutrition, 82(Suppl. 1), 222S-225S.

Zamora, D., Gordon-Larsen, P., Jacobs, D. R., Jr., \& Popkin, B. M. (2010 Oct). Diet quality and weight gain among black and white young adults: The Coronary Artery Risk Development in Young Adults (CARDIA) Study (1985-2005). The American Journal of Clinical Nutrition, 92(4), 784-793. 